\title{
The Marijuana Factor in a University in Ghana: a Survey
}

\author{
Samuel Adu-Gyamfi and Edward Brenya* \\ Kwame Nkrumah University \\ of Science and Technology (KNUST) \\ Ghana
}

Received 25.08.2015, received in revised form 11.09.2015, accepted 24.10.2015

This paper examines the marijuana usage among university students in Ghana. A focused interview was done to solicit information from users of the drug. It paid attention to thematic areas that are replete in the existing literature concerning the use of marijuana and its ramifications on student users of the drug. Attention is paid to the factors that drive the students to use the drug and its ramifications on their performance as students. Results and discussions that emanated from this severally qualitative study with some quantitatives should serve as bases for university administrators and lecturers to see the need to enhance their efforts in training peer educators and counseling units in universities in Africa and Ghana in particular.

Keywords: Marijuana, drug abuse, students, university in Ghana.

DOI: 10.17516/1997-1370-2015-8-11-2162-2182.

Research area: politology, history.

\section{Introduction}

Drug as an illegal substance is defined as any natural or artificially made chemical which is taken for pleasure, to improve someone's performance or an activity. Tobacco, coffee, marijuana, cocaine and heroin are all examples of drugs. ${ }^{1}$ There are three main types of drugs. They include depressants such as heroin, barbiturates, Stimulants such as cocaine, crack and amphetamines and hallucinogens such as marijuana (wee) and ecstasy. ${ }^{2}$ These drugs are ingested, inhaled, smoked, injected or snorted. Marijuana is the main focus and the substance is usually smoked. Users smoke marijuana in hand-rolled cigarettes called joints. Marijuana has many names, some of which are ganja, wee, ntampi, bongs, bonsam tawa, Indian hemp and so on. ${ }^{3}$ People smoke this substance for various reasons.

There are about one hundred and ninety million illicit drug users around the world. ${ }^{4}$ Most drug abusers are under the age of thirty. Marijuana is the most widely abused drug in the world. ${ }^{5}$ The illicit drug industry is now estimated to be over four hundred billion dollars per year. ${ }^{6}$ Drug use has been increasing among the young people worldwide especially marijuana. Most marijuana abusers are under

(C) Siberian Federal University. All rights reserved

* Corresponding author E-mail address: mcgyamfi@yahoo.com, ebrenya@gmail.com 
the age of thirty. ${ }^{7}$ Young people in America tend to experiment with alcohol, marijuana (wee), and other drugs during the middle school years and universities with a smaller number starting during elementary school. Estimates show that marijuana (wee) is the most widely abused drug in all parts of the world, with an estimated one hundred and forty one million people (or 2.4 per cent of the world's population) consuming it. ${ }^{8}$ In particular, large numbers of young people experiment with marijuana: as high as 37 per cent (one time use over the past year) of school children and young adults in some countries and 10-25 per cent for past month use. Overall, marijuana abuse is increasing in many countries while stabilizing in countries where it has reached high levels. ${ }^{9}$

Ghana, like other developing countries, has not been spared the problems of drug abuse, which is also one of the many outcomes of rapid social change. However, due to lack of accurate data, it is not possible to state exactly when drug abuse spread in our territory. It has been suggested that other than legal use of alcohol and tobacco in Ghana, the most common illegal drug of abuse is marijuana. ${ }^{10}$ Today, Ghana is recognized as a producer of marijuana for international drug trade with high consumption among the population (World Drug Report, 2000) and Ghana has been ranked as the number one user of marijuana in Africa and the third in the world. ${ }^{11}$

It was introduced into Ghana by colonial soldiers in Burma during the Second World War. Recent researches by sociologist have revealed other growing trends and illegal drugs which are abused in Ghana. A nationwide survey of high school students reported that $65 \%$ used drugs to have good time with their friends $54 \%$ wanted to experiment to see what it is like, $20 \%$ to $40 \%$ used it to alter their moods, to feel good, to relax, to relive tension and to overcome boredom and problems. $^{12}$
This work focuses on the abuse of marijuana among university students in Ghana. Attention is paid to some student users at the Kwame Nkrumah University of Science and Technology. Marijuana is an illegal drug made from the dried leaves and flowers of the hemp plant, which produces a feeling of pleasant relaxation if smoked: It is also the most commonly used illicit drug; considered a soft drug which consist of dried leaves of the hemp plant; smoked or chewed for euphoric effects. ${ }^{13}$

Marijuana abuse is a social canker that cuts across the social strata of Ghana. Policies have been implemented to eradicate the illicit abuse of hard drugs by respective governments, non-governmental organizations (NGOs), and stakeholders. In various universities in Ghana, authorities have laid strict rules to combat this issue but marijuana abuse is gaining grounds among university students. These strict rules seem not strict enough because marijuana use is gaining strong grounds in Ghanaian educational institutions especially tertiary institutions. However, these problems coupled with scant or limited literature that focuse on Kwame Nkrumah University of Science and Technology; a platform is created for us to do an additional work with emphasis on the causes and effects of marijuana among students.

Students in their academic environment need a good surrounding and a sound mind in pursuit of their academic work, it therefore becomes debatable when issues of marijuana come into play with academics and raises questions, such as, to what extent does marijuana affect the academic life of students? The general objective of this study is to investigate the increasing trend of marijuana abuse amongst university students and also to gather information from student users pertaining to what cause them to use marijuana and its effect it has on them. The following research questions have served as a guide in the discussion: 
Why do students smoke marijuana and what are the major factors that influence marijuana use among university (KNUST) students? What are the major effects of marijuana abuse on university students? Is it addictive and what are the options available to student users who wish to quit? What are the effects of marijuana abuse on academic performance of the user? And where do students get the substance from, how do they access it and the consequence of the use of the drug on KNUST campus and society at large?

\section{Matters arising from the literature}

During the past decade, a growing literature has emerged investigating the use of marijuana among the youth in Ghana and the world as a whole. There have been various articles written by many authors addressing this issue. Generally, cohorts have found evidence of the youth indulging in the abuse of marijuana, although the finding is often limited to specific populations. Marijuana, often called pot, grass, reefer, weed, and herb, Mary Jane or MJ- is a greenish-gray mixture of the dried, shredded leaves, stems, seeds, and flowers of Cannabis sativa-the hemp plant. Most users smoke marijuana in hand-rolled cigarettes called joints. Among other names, some use pipes or water pipes called bongs. ${ }^{14}$ According to Henry Bernstein in his journal gave out the different names of marijuana in some parts of the world. The South Asian provenance of narcotic use commonly term marijuana as Indian hemp (also in Nigeria). The term "bhanga" was very popular among marijuana smokers in the 1950s and 1960s, the report from the Paris-based OGD (Observatoire Geopolitique des Drogues) published in 1995:18 confirms that "bhanga" is still a common term in Cameroon and in East Africa. Marijuana is also widely known in Ghana as wee and "wee wee" in Nigeria and bonsam tawa (' devil's tobacco in Twi).
The authors identify the various names given to marijuana both locally and internationally. These names make identification by name easy for a layman who reads the article. Marijuana is used to brew tea and sometimes it is mixed with foods. Cannabis was very legal - largest agricultural crop in the world including USA. Cannabis hemp was the largest product used in making soft fibre for paper, medicines to mention a few. Cannabis was used as medicines, fluid extract- cannabis Indica was the name. ${ }^{15}$ There are more than 200 slang terms for marijuana according to the National Institute on Drug Abuse. ${ }^{16}$

Marijuana is a substance which can be described as an illegal drug made from the dried leaves and flowers of the hemp plant, which produces a feeling of pleasant relaxation if smoked or eaten. ${ }^{17} \mathrm{~A}$ drug produced in various forms from the dried leaves and flowers of the hemp plant, smoked or chewed, its recreational use is illegal in many countries. ${ }^{18}$

Increases in the use of most illicit drugs in adolescence has been a worldwide phenomenon since 1990 in many countries, (Centers for Disease Control and Prevention, 1991) with the most prevalent illicit drug used worldwide being marijuana (Reuter, 2006). ${ }^{19}$ This study shows how marijuana is abused worldwide. Through this information, marijuana abuse worldwide is exposed and necessary remedies are applied .Cannabis use is among the most common primary reasons for entering drug-related treatment worldwide. Furthermore, cannabis use often precedes the use of other drugs, which suggests that cannabis may cause further problems as a gateway drug in adolescent involvement in drug usage. ${ }^{20}$ Other illicit drugs used by adolescents are cocaine, heroin and crack-cocaine.

\section{Concept of marijuana abuse}

In Ghana, responses from users of cannabis as well as primary reports from the newspapers 
and published articles from journals suggest that the use of cannabis is prevalent in Ghana. The abuse of it is alarming. Helena Selby has reported that the abuse of drugs is one of the most popular social vices among the youth in Ghana. The fight against the use of drugs and especially drug addiction has become the priority of many world leaders. It has been argued that even though drug abuse and addiction is a challenging issue, the number of young people engaged in it increases every day. ${ }^{21}$ This makes us aware of how rampant the abuse of marijuana is gaining roots in Ghana but the author did not spell out how marijuana is acquired and distributed in Ghana that is making it most popular social vice.

Helena Selby agree with Samuel Adu-Gyamfi and Edward Brenya in the article re-hashing commentaries on the effects and potential benefit of cannabis that the substance mostly abused is marijuana (Indian hemp or wee). It is the cheapest drug and packaged at Gp50 per piece, which is very affordable. ${ }^{22}$ The use of heroin and cocaine is not very popular among substance abusers in Ghana due to their high cost. According to the 2007 World Drug Report by the UN Office on Drugs and Crime, $21.5 \%$ of Ghanaians aged from 15 to 64 smoked marijuana or used another cannabis product in $2006 .{ }^{23}$ Most abusers in this category are of school going age therefore exposing senior high school students and tertiary students as foremost abusers. The report continues by stating that Ghanaians use marijuana more than five times the world average which, as a result, has made Ghana the leader of African countries and third in the world in cannabis or marijuana. ${ }^{24}$ The report further indicates that Ghana ranks third in the world on marijuana use, behind Papua New Guinea and Micronesia with twenty-nine per cent each. This report creates awareness of the rate at which Ghanaians abuse marijuana in Africa and the world as whole. These information provided shows that Ghana, especially the youth faces a great danger of marijuana abuse in the near future and if strategic measures are not put in place the worst will happen. By identifying these problem in the tertiary institutions and Ghana as a whole, this work seeks to fill the gaps in the existing literature.

Adebayo points out that the introduction of marijuana in West Africa dates back to the twentieth century. ${ }^{25}$ The use of cannabis also known as wee and obonsam tawa ('the devil's tobacco') was associated with ex-servicemen as stated by Henry Bernstein in his work Ghana's drug economy and was also stated by Emmanuel Akyeampong in his work "Addiction to alcohol and drugs in urban environment" that West African soldiers who fought in Asia in World War II were the ones who introduced cannabis smoking on their return. ${ }^{26}$ Both Adebayo and Emmanuel try to trace the source of marijuana, its introduction into West Africa, Ghana and how its use and abuse became popular among the people in the country. Both of them failed to point out how the youth especially of school going age have strongly upheld the abuse of the illicit drug named marijuana.

$\mathrm{He}$ shares similar view with Elizabeth I. Omage in her article Illicit drug use and dependency among teenagers and young adult in Oredo local government area, Benin city, Nigeria that certain occupations noted for difficult and dangerous work such as night-soil men, prostitutes, criminals, fishermen, and farmers. Both authors state that in order to get extra strength and confidence these workers resort to the use of marijuana. They both reveal the effect marijuana has on their activity and without the substance they cannot work effectively and get maximum end results.

Cannabis use had much in common with akpeteshie (locally-distilled gin), feeding into a class and counter culture that rationalized what were criminal activities. ${ }^{27}$ Continuities studies 
are suggested in the ties between cocoa farmers and akpeteshie distillation in the colonial period and cocoa farmers and cannabis cultivation in the independent era. The intercropping of cocoa and oil palm made the distillation of akpeteshie from oil palm an important provider of cash in the period before the cocoa trees began to bear fruit. Since cocoa grows in forest areas, it was easy to conceal illicit distillation from the authorities. Likewise, high-quality cannabis (with high delta-nine-tetrahy-drocannabinol or THC levels) grows in deep forests, again providing cash for cocoa farmers in the period between harvests. With the decline in the world market price for cocoa from 1958, cocoa farmers may have been encouraged to diversify into cannabis cultivation, especially as the market expanded to include students. ${ }^{28}$

Rev. Vasco Abudu, president of the blue cross of Nigeria presented in the $8^{\text {th }}$ biennial international conference on alcohol, drugs and society in Africa, Abuja, Nigeria stated that there was an ongoing revelation which indicated that African farmers are shifting from traditional food crop production to cannabis at the detriment of the consumers mostly youths.

This revelation by Rev. Vasco Abudu falls in line with T.A Lambo when they greed on the fact that farmers are shifting from their cultivation of crops to marijuana. Lambo limited this practice to Ghana only but Rev.Vasco created the awareness that the syndrome is not only with Ghanaian farmers but it is an ongoing trend across Africa. This practice should not be entertained by any developing country. The problem with both authors is that, they did not rightly spell out the measures the various governments have taken to curb this abysmal canker that is fast growing in most African countries.

Again in the Brong Ahafo region, the heartland of cocoa cultivation, farmers switched to maize cultivation to feed the expanding urban centers when cocoa prices fell. A 2001 police report indicates that many farmers in the region now find the cultivation of cannabis more lucrative than maize. ${ }^{29}$ Today, marijuana abuse has taken a major toll on the youth especially senior high school and university students. ${ }^{30}$ The world drug report from the united nation in 2000 stated that in today's world, children and young people are increasingly misusing alcohol and marijuana at an alarming rate (World Drug Report 2000). The average age of first use is between 11 and 12 years (Kandel and Logan, 1984). Among school children, this usually starts in school or within the communities where they live (National Institute on Drug Abuse, 2003). Freeman Koryekpor Awlesu released in his article "Todays Ghana" that the total number of 50,000 drug users in Ghana. 35,000 were students from senior high schools and tertiary institution aged between 12 and 35 years while the remaining 15,000 were adults with 9, 000 being males and 6,000 females. ${ }^{31}$ Again, students in the senior high schools and at the tertiary levels have also been identified as users of marijuana in Ghana. ${ }^{32}$

Freeman's whole reason behind this data was to showcase the level of marijuana abuse in the secondary and tertiary institutions and what authorities in the institutions are doing to control this plight and Samuel Adu-Gyamfi also bears witness to freeman with the rate at which secondary and tertiary students abuse marijuana. Freeman however, was not specific with the actual figures that are connected to the tertiary level especially the Kwame Nkrumah University of Science and Technology (KNUST). This work seeks to identify the number of marijuana abusers in the school, causes and effect of marijuana. Future abusers are almost always introduced to both legal and illegal substances in adolescence by friends who hold favorable attitudes toward drugs and these adolescents grow up with this 
social vice, gain admission into senior high schools and universities and continue the abuse.

Samuel Adu-Gyamfi and Edward Brenya have argued that some years ago "Rastafarians were known to be the popular users of marijuana; now both Rastafarians and some members of the general populace have been noted for using marijuana. ${ }^{33}$ Arguably, more people may be using and abusing drugs in Ghana than it is estimated. The Ghana Demographic and Health Survey's (GDHS) Report for 2010 stated that the region in recent times is not only a transitory route but also a consumer market of hard drugs. Reports of foreigners financing "wee" farms in Ghana points to Jamaicans and other WestAfrican nationals. ${ }^{34}$

Contrary to popular beliefs, marijuana usage can be very addictive. ${ }^{35}$ Scientific research has found that one in ten marijuana users will become addicted to the drug. And if one begins in adolescence, that number rises to one in six. ${ }^{36}$ This study proves how addictive and how dangerous marijuana abuse is. Regardless of this knowledge, it is perceived that students continue to smoke and abuse marijuana.

\section{Statistics}

\section{of marijuana abuse worldwide}

Estimates show that cannabis is the most widely abused drug in all parts of the world, with an estimated 141 million people (or 2.4 per cent of the world's population) consuming it. In particular, large numbers of young people experiment with cannabis: as high as 37 per cent (one time use over the past year) of school children and young adults in some countries and 10-25 per cent for past month use. Overall, cannabis abuse is increasing in many countries while stabilizing in countries where it has reached high levels. ${ }^{37}$

According to the Narcotic Control Board of Ghana, there were 145 cases of drug abuse in
2003 as compared to 767 cases in 2010 within the age group of 15-20, an average percentage increase of 61 per cent annually (Masahudu 2012). According to the 2007 World Drug Report by the UN Office on Drugs and Crime, $21.5 \%$ Ghanaians, aged 15 to 64 , smoked marijuana or used another cannabis product in 2006. The report continues that Ghanaians use marijuana more than five times the world average, which, as a result has made Ghana the leader of African countries and the third in the world in cannabis or marijuana use, behind Papua New Guinea and Micronesia (Selby, 2012). ${ }^{38}$ Currently, the use and abuse of drugs have expanded to include the youth and kids (Ametepey, 2010). The 2007 World Drug Report by the UN Office on Drugs and Crime also showed that $21.5 \%$ of Ghanaians, aged from 15 to 64 , smoked marijuana or used another cannabis product ${ }^{39}$

Fourteen percent of patients admitted to hospitals have marijuana and addiction disorders. ${ }^{40}$ Almost 20 percent of all Medicaid hospital costs and nearly $\$ 1$ of every $\$ 4$ Medicare spent on inpatient care is associated with substance abuse. ${ }^{41} 70$ percent of individuals in state prisons and jails have used marijuana regularly. The economic burden in the United States for addiction of marijuana is twice that of any other disease affecting the brain, including Parkinson's and Alzheimer' Disease, as well as all the others. ${ }^{42}$

An estimated 150 million adolescent's worldwide use marijuana. Adolescent smokers are also subject to more immediate health consequences, such as respiratory and non-respiratory effects, changes in serum cholesterol and nicotine dependence and withdrawal. Moreover, once adolescents start smoking, the impact of prevention programs, whether on experimental or regular smokers, is small and inconsistent across studies. It is estimated that adolescent smokers who reach 
a consumption level of at least 100 rolls will continue to smoke for another 16-20 years. ${ }^{43}$

Among adolescents in the early stages of smoking onset, alternating periods of smoking and abstinence are common. Yet longitudinal studies show that only 3-12\% of adolescent daily or regular smokers and $10-46 \%$ of adolescent non-daily or occasional smokers no longer smoke 1-3 years later. This suggests that the likelihood of achieving abstinence, although generally low, is greater if a cessation attempt occurs at lower levels of consumption. ${ }^{44}$

The World Health Organization (WHO) ranks the United States first among seventeen European and North American countries for prevalence of marijuana use. And more users start every day. ${ }^{45}$ More than 94 million Americans have tried marijuana and it remains the most widely used illicit drug in the nation. ${ }^{46}$ In 2008, an estimated 2.2 million Americans used marijuana for the first time; greater than half were under $18 .{ }^{47}$ The Drug Abuse Warning Network (DAWN), a system for monitoring the health impact of drugs estimated that in 2008, marijuana was a contributing factor in over 374,000 emergency department (ED) visits in the United States with about two-thirds of patients being male and 13 per cent between the ages of 12 and $17 .^{48}$ Data from the National Institute on Drug Abuse in America found out that in 1993 marijuana comprised approximately $8 \%$ of all treatment admissions but by 2009 , that number had increased to $18 \%{ }^{49}$ For those under 18 , marijuana related treatment admissions increased by 188 percent from 1992 to 2006 while other drugs remained steady. ${ }^{50}$ Data from the United States is corroborated with data from other countries. In the European Union, the percentage of marijuana as the primary reason for entering treatment increased by 200 percent from 1999 to 2006, and currently stands at around 30 percent of all admissions. ${ }^{51}$ The Netherlands has the highest rate of marijuana addiction in Europe. ${ }^{52}$

\section{Causes and effects}

\section{of marijuana abuse amongst students}

World health organization's annual report on drugs in 2007 states causes of marijuana abuse amongst students can be linked to many reasons, young adults looking for peer acceptance or wanting to appear mature or "cool" might decide to use substances. ${ }^{53}$ Thus associating and socializing with peers who are into substance use provides an opportunity for access to these substances that can encourage experimentation and continued use. ${ }^{54}$ Social pressures, from peers, family, and societal role models are at the top of the list of reasons why adolescents initiate substance use and their continued use may be socially and environmentally driven. ${ }^{55}$ Peer influences form the major factor for marijuana abuse, Henry Bernstien in his journal wrote that friends influence peers with an explicit ideological line on marijuana consumption, inflected by their passion for reggae and present it as life-enhancing: good for ailments (asthma, appetite loss), reading, contemplation and sense of self - and sexual potency. This is combined with a similarly 'ideologised' rejection of other drugs including alcohol. ${ }^{56}$

Among university students the major cause of marijuana abuse is peer pressure. This is when friends have strong influence on the individual. This is very evident in hostels on and off the main campus of the university. Some also may feel they need marijuana and other drugs to help them escape from problems at home, at school, or with friends (Pope and Yurgelun-Todd, 1996).

Y. H. Affinih in his article states that one cause of marijuana abuse is that, youth are attracted to cannabis use not just because of the participation in Rasta culture. Many seemed to believe, erroneously, that cannabis enhanced their learning capacity. This belief then draws on the tradition that associated cannabis use with hard work. ${ }^{57}$ 
The abuse of marijuana has a dire effect on both students and their environment. Medical research on effects of marijuana abuse is plentiful (Margolis and Popkin 1980). ${ }^{58}$ Generally, results of studies show that marijuana causes changes in organs and systems of the body. These changes, some of which do not augur well for individuals who use marijuana heavily. ${ }^{59}$ Marijuana use affects the male reproductive system..$^{60}$ Kolodny, Masters, Kolodner, and Tbro's (1974) sample of 18 to 28 -year old male marijuana smokers had sharply reduced testosterone levels when compared to a nonsmoking control group. ${ }^{61}$ The subjects of these authors' sample used marijuana at least four times per week for six months or more.

The use of marijuana is to some a lifestyle and to others a lifeline. It is a delicate balance which can make simple tasks become very frustrating. For instance, Dr. Jule Holandgets paranoid, panic attacks, anxiety attacks, disorganized thinking and disoriented when uses marijuana. ${ }^{62}$ Again, Carl Hart of Columbia University argued that it causes disruption in memory, disruption in inhibitory control, makes one slow at cognitive functioning but they are temporary but pronounced. The area of the brain that is basically affected is the pre frontal cortex (planning, thinking, coordination). It causes impairment in driving and makes people turn without looking carefully. ${ }^{63}$ For young people marijuana, the use of marijuana can produce adverse physical, mental, emotional and behavioral effects. It can impair short-term memory and judgment and distort perception. ${ }^{64}$ Because marijuana affects brain systems that are still maturing through young adulthood, its use by teens may have a negative effect on their development. ${ }^{65}$ Marijuana use directly affects the brain specifically the parts of the brain responsible for memory, learning, attention and reaction time. ${ }^{66}$ This effect of marijuana towards the brain really affects student's especially tertiary students because the primary reason for coming to school is academics and anything short of that is a secondary matter

However, the effects of marijuana abuse also drag the progress of the nation especially in instances where users lose their minds and are sent to mental institutions. With the state of conditions of Ghana's mental hospitals and the number of users increasing by the day. Pressure will be on the health resources of the country. Significantly, the government would be compelled to pump some of its scarce resources into taking care of these patients. The use of marijuana in Ghana has become one of the main causes of mental illness among the youth and adult today as some end up in psychiatric hospitals as stated earlier while others find themselves on the streets and in prayer camps. ${ }^{67}$

Today's research from fifteen (15) psychiatric hospitals in Ghana has shown that about $70 \%$ of inmates in those hospitals were youth between the ages of 18 to 35 years. ${ }^{68}$ This clearly spells out the rate at which youth especially university students are abusing marijuana.

In 2005, the three psychiatric hospitals (Ankaful, Accra and Pantang) recorded a total of 86,003 outpatient attendances (Ofori-Atta et al 2010) with mental and behavioral disorders due to psychoactive substance use representing $22.8 \%$ of the in-patient diagnosis.62 The Outpatient Monthly Morbidity Returns records from the Psychiatric Unit of the Regional Hospital, Sunyani, for 2012 for instance, indicates that of the 2,284 clients who reported with various psychiatric illnesses for the year, 594 (26\%) were substance abuse related cases, mostly marijuana. ${ }^{69}$

Since smoking of marijuana is highly addictive students will find every means to smoke if the substance is not readily available. This is where stealing money from others sets in 
because he is not financially stable to buy a roll of marijuana to smoke. Stealing will lead to lies and all sort of social vices, which eventually defame the good name of the school.

\section{History of marijuana use}

The use of marijuana has become a social practice especially among youth of school going age. The abuse of marijuana has earned Ghana a third place in the world ranking of abusers. In order to understand the growing interest of the substance abuse, there is the need to identify the history of marijuana abuse in Ghana and the world at large. This chapter seeks to look at the general history of marijuana, medicinal history of marijuana usage and its origin in Africa.

The cannabis plant originates from central and southern Asia. ${ }^{70}$ Charred cannabis seeds found at an ancient burial site now Romania showed that people have been smoking it since the 3rd millennium $\mathrm{BC}$, for instance, in 2003 a leather basket full of cannabis seeds and leaf fragments was found next to the 2,500-2,800 year-old mummy of a shaman in China. ${ }^{71}$ Other cultures known to have used cannabis include the Hindus and Nihang Sikhs from ancient India and Nepal, these cultures used the "Sanskrit" term for the herb. ${ }^{72}$ An equally ancient drug called «soma» was also sometimes associated with cannabis. ${ }^{73}$

Nonetheless, cannabis didn't end with the Asians, it was also known by the ancient Assyrians who knew about its psychoactive properties and used it in some of their religious ceremonies, referring to it as "Qunubu" - way to produce smoke - and a possible precursor of the modern form of the word «cannabis.» ${ }^{74}$ From there, the drug moved into the cult of Dionysus, and the regions of Greece and Turkey. ${ }^{75}$ The Scythians may have been one of the most prominent cultures to use cannabis for religious or spiritual reasons, but they're certainly not alone. ${ }^{76}$ Some writers have even claimed that ancient Jews and early
Christians may have used the drug, basing their theories on the similarities between the terms "Qannabbos" (cannabis) and the phrase "qené bósem" (aromatic cane) in old Hebrew. ${ }^{77}$ The early Sufi Muslims also used the drug ${ }^{78}$.

In slightly more recent times, a study published in the South African Journal of Science referred to pipes «dug up from the garden of Shakespeare's home in Stratford-upon-Avon" had traces of cannabis. ${ }^{79}$ This was confirmed via chemical analysis after research scholars theorized that the «journey in my head» Shakespeare wrote about in Sonnet 27 and the «noted weed» he mentions in his Sonnet 76 were references to the drug and its use.

\section{Medicinal history of marijuana}

Marijuana has been used for healing and medicinal purposes since ancient times. The plant has been grown for fiber and as a source of medicine for several thousands of years. ${ }^{80} \mathrm{Up}$ until 500 A.D, the first evidence of medicinal use of cannabis was in a journal published during the reign of the Chinese Emperor Chen Nung 5000 years ago. ${ }^{81}$ Cannabis sativa has been used therapeutically to the present day and its products have been widely noted for their effects, both physiological and psychological throughout the world. Although the Chinese and Indian cultures knew about the properties of this drug from early times, this information did not become general in the Middle East and Europe until after the fifth century A.D., when travelers, traders and adventurers began to carry knowledge of the drug westward to Persia and Arabia. ${ }^{82}$

The drug and its uses then moved across North Africa, then moved to Latin America, the Caribbean and finally entered the United States in the early decades of this century. ${ }^{83}$ The first Western physician to take an interest in marijuana as a medicine was WB O'Shaughnessy, a young 
professor at the Medical College of Calcutta, who had observed its usage in India. ${ }^{84} \mathrm{He}$ gave cannabis to animals in an experiment, satisfied with the results, he began to try it on patients suffering from rabies, rheumatism, epilepsy, and tetanus ${ }^{85}$ In the United States, medical interest in marijuana use was evidenced in 1860 by the assembling of a Committee on Cannabis Indica of the Ohio State Medical Society, which reported on its therapeutic applications. ${ }^{86}$ Between 1840 and 1890, Walton states that more than 100 articles were published recommending cannabis for one disorder or another. ${ }^{87}$ Concern about cannabis as an intoxicant led the government of India to establish the India Hemp Commission of 1893-94 to examine the entire questions about the usage of cannabis in India.

Paralleling the question over cannabis use in the latter half of the 19th century was the growing medical use of other medications superior to cannabis in their effects. Consequently, medical use of cannabis declined and cannabis began to lose support in the medical profession. During the years between 1856 and 1937, cannabis lost its image as a medicine and was left with a disreputable image as an intoxicant. Strong public reaction coupled with a campaign in the public press led to a federal anti-marijuana law in 1937 in the United States of America.

In African culture, cannabis was used in ancient times in a medicinal capacity to treat common conditions such as dysentery and malaria. ${ }^{88}$ Black Jamaicans used marijuana as a panacea for illnesses such as dysentery, sunstroke, phlegmatic tempers, indigestion, and loss of appetite, lisping, and muddled intellect, among others. ${ }^{89}$

\section{Origin of marijuana in Africa}

The use of marijuana by the indigenous people of Africa can be traced back to the 14th century Ethiopia..$^{90}$ Since marijuana did not originate in Africa, the ancient tribes who used it had to acquire it through trading with the Asians. ${ }^{91}$ Archaeologists now believe that marijuana was introduced to African societies by trading goods with their Arab neighbors. ${ }^{92}$ Soon, through seed sharing and careful cultivation practices, cannabis culture had spread to other tribes throughout Africa, giving birth to a commodity that would become more valuable than gold. Originally, African tribesmen chewed cannabis leaves, but they soon learned the art of smoking the plant, which changed African culture in many ways. ${ }^{93}$ New skills, like pipe-making, had to be learned and smoking marijuana became a large part of ritual and recreation which was performed in groups. ${ }^{94}$

In West Africa, Sierra Leone apparently cultivated cannabis (locally called diamba) long before other West African countries, and by the colonial period, at least, indigenous midwives were using cannabis as anesthesia during difficult childbirth. ${ }^{95}$ Fishermen used it as an aid for hard work and by the 1920s, when cannabis possession became illegal, most fishermen were arrested. ${ }^{96}$ From the 1930s, Sierra Leoneans began to explore a market in cannabis in other British West African colonies. ${ }^{97}$ Capitalizing on Freetown's importance as a major port and a larger Krio diaspora in the service of British colonialism in West Africa, cannabis from Sierra Leone began to make its way to other West African colonies. The colonial governments in the Gambia and the Gold Coast would flag these developments and insist that the government in Sierra Leone help curtail these activities.

In Ghana and Nigeria, soldiers who fought in Asia during World War II were mainly the ones who introduced cannabis smoking on their return. ${ }^{98}$ The common name for cannabis in Nigeria and Ghana is Indian hemp, which suggests its Asian provenance. The substance, cannabis was illicit from its very introduction into Nigeria 
and Ghana, its introduction by colonial soldiers and the association of the military with a life of violence gave cannabis a social reputation that connected it immediately with disorder. ${ }^{99}$ It is striking how cannabis quickly joined ranks with illicitly distilled gin (akpeteshie in Ghana) in the colonial period, both illegal and underpinned by a shared popular culture. Initially used by servicemen, and certain occupational groups associated with dangerous work, cannabis use had much in common with akpeteshie, feeding into a class- and counter-culture that rationalized what were criminal activities. ${ }^{100}$

What popularized the use of cannabis in West Africa among the youth was the global spread of reggae music and the Rastafarian movement in the 1970s. ${ }^{101}$ In Senegal, the Baye Faal branch of the Mouride Islamic brotherhood is characterized by dreadlocks, colorful patchwork clothes, and the sacred and secular use of cannabis and the perception of the lion as a sacred symbol. Neil Savishinsky, who has worked on the Baye Faal movement and the global spread of Jamaican popular culture notes that the smoking of cannabis among the Baye Faal is a recent movement, strongly related to the increasing popularity of reggae and Rastafarianism in Senegal. ${ }^{102}$ When Nigeria and Ghana were presented with the phenomenon of secondary and university students using cannabis, this then was the layered social context of the drug.

Youth were attracted to cannabis use not just because of their participation in Rasta culture. Many seemed to believe, mistakenly, that drugs such as marijuana enhanced their learning capacity. ${ }^{103}$ This belief then throws light on the tradition that associates cannabis use with hard work. Considering that many of secondary and university students in the 1960s and 1970s were first generation metropolitan and often the first in their families to enter secondary and tertiary institutions of education, they may not have been alien with the association of cannabis and hard work, and the pressure to do well in school turned them in this direction. But the emphasis here is on physical and not intellectual work. The Ghanaian Daily Graphic in April 1994 reported a survey conducted among girls and boys secondary schools, which sought to understand the significant differences in academic performance. ${ }^{104}$ A survey, reportedly undertaken by the Ghana Education Service established that girls schools are performing academically better than the boys schools and the phenomena might not be unrelated to drug abuse. ${ }^{105}$ By 1999 the National Union of Ghana Students (NUGS), the University Students' Association (USAG), had added its voice to the campaign against marijuana use among secondary and tertiary students. ${ }^{106}$ Data were analyzed and compared on measures relating to substance use, reason for use, how did the user start using the substance, perceptions of friends about the user, the health effect of the substance use on the individual and effect of the substance on their academics. Results were then compared to related literatures.

\section{Observation of marijuana joints}

This was carried out in the traditional halls and hostels on campus and off campus. Sales points for marijuana on campus were mainly in Brunei, abusers off campus made purchases at hostels in Kentinkrono specifically Georgia and Crystal Rose, splendor hostel, at Ayigya (Tech Junction). ${ }^{107}$ Students were not the only ones seen visiting these marijuana joints, other town people who abuse marijuana were present specifically in the joints located off campus and sometimes on campus. $^{108}$

Places where students meet to smoke marijuana were mostly bushes located around the Unity Hall canteen, specifically behind where the food is prepared before taken to the canteen and there was one located University hall, 
specifically the bush between University hall and Shaba. ${ }^{109}$ This places where students go to use the substance is referred to by the users as "Bingy". ${ }^{110}$ Abusers could enter the bingy anytime to smoke their rolls of wee. During noon and late night was when they mostly meet in the bingy. ${ }^{111}$ Students located off campus, smoked the marijuana in their rooms. That privacy permitted them to smoke as much as they wanted without restraints. The substance are kept in rooms. Often 'Nights of smoking' which is the assembling of friend users over and smoking in the night were observed. ${ }^{112}$ The substance abuse was observed to be high among students in hostels off campus than in the traditional halls. It was observed that the halls have strict rules concerning illegal use of drugs, also due to the number of persons in each room accommodated, thus four, there is difficulty in smoking the substance in the hall and therefore they resort to these hideouts on campus

\section{Results of survey}

It was analyzed from the data that, the major factor that influences the abuse of marijuana among students in this university is peer influence. From the 50 sampled students who use marijuana, majority responded that their contact with marijuana came through friends or peer groups and others stated factors such as adventure, curiosity and personal choice. The tables below provide the demographic characteristics of the total number of students interviewed in KNUST.
Table 4.1 shows the educational levels of peer influence. As shown in the table most student abusers of marijuana came into contact with the substance in the SHS through peers representing sixty four (64\%), followed by the university representing sixteen $(16 \%)$, followed by JHS representing fourteen (14\%) and peer influence in the neighborhood representing six (6\%). It becomes vivid that majority of students who abuse marijuana came into contact with the substance through peers in senior high school.

Table 4.2 shows the reasons student abusers smoke marijuana. As shown in the table, the major reason for the abuse of marijuana is to feel high, that is, to get to a certain level of ecstasy; they term this feeling as "feeling iray." 13 The respondents stated that the feeling is inexplicable and that the user feels as if he is on top the world, no feeling can be compared to 'this state'. Following this, the other reasons given by the respondents were that, smoking marijuana is done for fun. The smoking of marijuana is an activity to whirl away time and there is no ulterior motive for participating in this activity. To a more personal extent some student users stated that, they use the substance to increase their self-esteem, to boost their confidence levels so as to be able to undertake activities such as approaching a lady, addressing a large crowd and engaging in a fight.

The use of the substance gives them the extra panache to do things they rarely do. Aside these major reasons, others also stated that they use

Table 4. 1: Educational levels of peer influence $(\mathrm{N}=50)$

\begin{tabular}{|l|c|c|}
\hline \multicolumn{1}{|c|}{ Stage of peer influence. } & Number of student users & Number in percentage. \\
\hline J.H.S & 7 & $14 \%$ \\
\hline S.H.S & 32 & $64 \%$ \\
\hline University & 8 & $16 \%$ \\
\hline Neighborhood & 3 & $6 \%$ \\
\hline
\end{tabular}

Source: Field survey in KNUST on April 4, 2015. 
the substance to stay active and meditate. Some respondents also stated that the use of marijuana helps relax their nerves and make them very comfortable and also the smoking of marijuana makes them forget their problems. Concerning the effects of marijuana on the student user, the health complications and the effects on their academics whether negative or positive will be analyzed. From the data collected, most students users affirmed that the use of marijuana have negative impact on their life. Some also responded that it gives them health complications such as chest pains, itchy eyes, dehydration and chronic cough.

Aside health complications, there are other minor negative effects such as the user becoming dull, sleeping a lot and becoming extremely dizzy. Most users responded that the smoking of marijuana makes them very hungry and if after smoking there is no food available they became furious and quiet aggressive. Another peculiar problem is the feeling of emptiness without the substance, with this statement, there is a relation between Hall W and Degenhard L in their book, "adverse health effects of non-medical cannabis use" which states marijuana is highly addictive. It was observed that the drug poses little or virtually no effect on the academics of some student users stating that they can be with or without marijuana.

Table 4.2 shows the effects marijuana has on academics. As shown in the table, sixty six percent $(66 \%)$ of the respondent stated that the abuse of marijuana have positive impacts on their academics, while twenty two (22\%) stated it poses harmful effects on their academics and twelve percent (12\%) stated that it has virtually no effect on their academics. The sixty six (66\%) respondents who stated that it impacted their academics positively gave reasons such as the use of marijuana increase their productivity, study for long hours, gives them retentive memory and high concentration during and after lectures.

Also, twenty two percent (22\%) of the respondents stated that marijuana has negative effects on their academics, giving reasons such as being tensed up making it difficult to study during learning hours and also making them sleep

Table 4. 2: Reasons why student abusers smoke marijuana $(\mathrm{N}=50)$

\begin{tabular}{|l|c|c|}
\hline \multicolumn{1}{|c|}{ Reasons for smoking marijuana } & Number of student users & Number in percentage. \\
\hline Feeling high & 18 & $36 \%$ \\
\hline For fun & 14 & $28 \%$ \\
\hline To relax & 8 & $16 \%$ \\
\hline To be active & 3 & $6 \%$ \\
\hline
\end{tabular}

Source: Field survey in KNUST on April 4, 2015

Table 4. 2: Effects marijuana on academics $(\mathrm{N}=50)$

\begin{tabular}{|l|c|c|}
\hline \multicolumn{1}{|c|}{ Effects on academics } & Number of student users & Number in percentage. \\
\hline Positive & 33 & $66 \%$ \\
\hline Negative & 11 & $22 \%$ \\
\hline No effect & 6 & $12 \%$ \\
\hline
\end{tabular}

Source: Field survey in KNUST on April 4, 2015 
a lot, this will go a long way to affect their grades eventually lead to rustication or withdrawal. A respondent gave an instance when he used the substance during exams week and stated "I smoked the substance a night before his paper in the morning, I woke up to realize the next morning that my mates have already written that paper." 114 He explained that the marijuana made him dizzy and made him forget himself till the next day.

Accessing how marijuana finds its ways in the jurisdiction of university, considerable measure will be given to how students gain access to marijuana.

Table 4.3 shows the source of marijuana in the university. Students access the drug both on and off campus with the statistics off campus higher than on campus. From the table, Sixty four percent $(64 \%)$ of the respondents affirmed that they buy the substance from various locations outside the university campus, some location as stated by the respondents are Krofrom, Ayigya (Tech junction), Atonsu, Aboabo, Adum and Ayeduase. ${ }^{115}$

Twenty eight (28\%) responded that they buy the substance from friends in their hostels and halls of residence. Some hostels stated were Crystal rose, Sun city, Georgia, Evandi, Master brains, Dellisa Annex and splendor. Also, eight percent $(8 \%)$ of the respondents access the substance from their homes, which is growing the substance in their backyards and also from friends in their neighborhood.
There was also an informant who hinted that the substance was accessed at a place arranged for wee smokers in the bush on campus called "bingy". ${ }^{116} \mathrm{He}$ stated categorically that there are two main "bingys" on campus, one located behind Katanga and the other located behind the bushes of unity hall canteen. In relation to the price of marijuana, a respondent disclosed that, prices varied from location to location. He stated, "Marijuana is cheaper when it is coming from town in whole sale as compared to when it is distributed, retailers add certain amounts to it as profit"117. On campus, one roll of marijuana ranged between one cedi and one cedi fifty pesewas. Off campus, the price of a roll of marijuana ranged between two cedis and three cedis. He stated that the patronage for the substance is very high and that, it does not last more than three days on delivery. In other parts off campus, that is Kentinkrono where hostels like Georgia, Crystal Rose, Gaza, Sun City and Anglican hostel are located, prices of marijuana are very expensive, the respondent also stated that one roll of marijuana ranged from ten to twenty cedis. ${ }^{118}$ The reason for these exorbitant prices is due to the fact that, students in these areas are considered rich. He went on to state that the users really patronized the substance regardless of the high prices.

Concerning the consequences of the use of marijuana on campus, some respondents affirmed that the abuse of the substance make them aggressive and prone to violence, hence the need

Table 4. 3: Sources of marijuana in the university $(\mathrm{N}=50)$

\begin{tabular}{|l|c|c|}
\hline \multicolumn{1}{|c|}{ Sources of marijuana. } & Number of student users & Number in percentage. \\
\hline Outside the boarders of the school & 32 & $64 \%$ \\
\hline Friends in hostels & 14 & $28 \%$ \\
\hline Home & 4 & $8 \%$ \\
\hline
\end{tabular}

Source: Field survey in KNUST on April 4, 2015 
to find out if there is a link between the substance abuse and social vices in and around the university campus. Over a period of the time, social vices such as petty theft, robbery, snatching of items have been alarming on KNUST campus. From the research conducted, it was observed that people have certain perceptions about users of marijuana. Some people think they are considered as bad persons, rude, irresponsible, violent, stubborn, quick tempered and aggressive. Although stated by the users that the drug made them aggressive there has not been an instance where a certain behavior demonstrated by a student have been attributed to the use of marijuana.

The use of illicit drugs in the school is highly prohibited, especially the use of marijuana. According to the student guide, given to every student on admission to the school, it clearly states that it is an offence and a breach of university regulation to indulge in the sale and use of narcotic and illicit drug ${ }^{119}$. Failure of a student to observe the rules and regulation will be liable to one of the following penalties. ${ }^{120}$ Either the student is warned, reprimanded, rusticated for a stated period, suspended from the university for a stated period, or outright dismissal of the student from the university. ${ }^{121}$

\section{Discussion}

Accessing the information above, it is evident that the use of marijuana is prevalent in the university. The reason for the use of wee is contradicted with the reason stated by Emmanuel Acheampong in his article "Diaspora and Drug Trafficking in West Africa: A Case Study of Ghana", he stated that marijuana was used for occupations noted for arduous and dangerous work like stevedores, night-soil men, prostitutes, criminals, fishermen, and farmers but from the research users stated that they smoked marijuana to feel good, to increase self-esteem, to have fun, to boost their confidence and so on.
These reasons given above falls in line with the reasons given by the Ministry of Health/World Health Organization (2003), "national survey on prevalence and social consequences by substance (drug) use among second cycle and out of school youth in Ghana Research Report" stated that the use of marijuana among the youth was centered on the perceived benefits such as enabling them to study, to do hard work, to get rid of shyness, and to forget about their problems, for fun, and due to peer pressure from fiends.

In relation to the effect of marijuana use on the academics of the students, the reasons stated were both positive and negative. Sixty six percent $(66 \%)$ of the respondents stated that the use of the substance had positive on them, twenty two (22\%) of respondents stated that the substance had negative impact on them. The reasons for the positive impact stated by the respondents were that marijuana gave them more capability to learn for more hours, retentive memory and high concentration level. Scholars like Finnell and J.D Jones in their article "Marijuana, Alcohol, and Academic Performance,» state that the negative use of marijuana on students result in poor academic performance, decreases students chances of learning essential skills and successfully completing school. The article further states that students will not remember lectures or will not be able to recall materials previously stored. Studies also show that heavy marijuana smokers perceive the use of marijuana as poor academic adjustment. The negative effect on their academics as stated by the respondents include: heavy sleeping, loss of memory, coughing which makes them unable to sit and learn for longer periods. In the research, it was revealed that the use of marijuana was highly addictive. Eighty four percent (84\%) of the respondent stated that the use of marijuana was addictive and without the drug use makes them 
uncomfortable. This claim by the respondents clearly agreed with many scholars, researches and medical personnel's. A report from the ministry of health/ World Health organization and the journal by L.L Simmon " the everything health guide addiction and recovery" states that the use of marijuana is highly addictive and if care is not taken the user will smoke until their brain damages or have lung cancer.

The other twelve percent (12\%) stated that they do not think marijuana is addictive and they smoke marijuana occasionally when they meet as friends at clubs, house parties, drinking spots among others. They state the claim that they just smoke marijuana at these times and that they can stay away from marijuana for a long time if there is no social gathering where friends meet and smoke the substance. Over the past few years, there has been an increasing trend of marijuana abuse amongst university students in Ghana. The situation raises questions about the depth of understanding of factors influencing the abuse of marijuana amongst university students. The study therefore sought to examine the increasing trend of marijuana abuse amongst university students in Ghana, the causes and effect of the substance, using KNUST as a case study. The research was also to suggest strategies that may help to curb this alarming social canker. More specifically, the research has identified causes of the drug use greatly associated with peer influence. The other causes of the drug use were family practice, for curiosity sake, adventure that is trying something new, personal choices and also as a remedy for stress, burdens, inability to study and build confidence.

Fifty (50) students were selected, both males and females, undergraduates and postgraduates, students residing on campus and off campus. Amongst fifty respondents used in the survey, seventy six $(76 \%)$ were males whiles twenty four percent $(24 \%)$ of the respondents were females
The study generally revealed that peer influence was the main cause of the substance abuse in the university. It also revealed that peer influence did not mostly start in the university, they started from various places before they got enrolled in the school. Those who were influenced in the university were few. Those who started from junior high school were nineteen percent (19\%). Those influenced in the senior high school were sixty four percent (64\%) eleven percent $(11 \%)$ of the respondents stated that they were influenced by peers in the university. The remaining six (6\%) were influenced by peers in neighborhoods they stayed or once stayed.

The study revealed relatively high percentage of students who used the substance were enormously residing off campus. The study also revealed that twenty-two percent ( $22 \%$ ) of the students who use marijuana had negative effect on their academic performances and sixty six percent $(66 \%)$ respondents stated that it impacted their academics positively. The other twelve percent (12\%) stated that marijuana use has virtually no effect on their academics and they see nothing wrong with the use of marijuana in school. It revealed that most of the marijuana abusers had complications with the use of the substance. Complications stated were chest pains, itching eyes, dehydration and chronic cough and so on. Aside these major effects there were minor effects such as extreme hunger after the drug use, becoming dull, sleeping a lot and extreme daze and so on.

It was also noticed that the prices for marijuana also differed from location to location. . On campus the price for one roll of marijuana was cheaper than off campus. One roll of marijuana ranged between one cedi and one cedi fifty pesewas. Off campus prices also varied at Ayeduase, Bomso and new site. Their prices were a little bit higher to campus, a respondent stated that one roll of marijuana 
there was between two cedis to three cedis. In Kentinkrono, where student resided it was known that their prices were much higher as compared to campus, Ayeduase, Bomso and New Site. In Kentinkrono, there was a business boom to the extent that the substance was soldout within three days.

Interestingly, all of the abusers in this research agreed that they are aware that the abuse of marijuana is illegal in the university.
This made a total of hundred percent (100\%) of abusers who were interviewed in the university concluding that they were not ignorant of the law both in the university premises and the nation as a whole. They were also aware of the penalties involved in the abuse of drugs. The survey generally revealed that student users of marijuana did not mind the consequences. They perceive that they would never be caught during their stay in the University.

1 Samuel Adu-Mireku, "Prevalence of Alcohol, Cigarette, and Marijuana use among Ghanaian Senior Secondary Students in an Urban Setting", Journal of Ethnicity in Substance Abuse, vol. 2 no.30, (2003): 10-20..

2 United Nations "United Nations Office on Drugs and Crime (UNODC),2008 World Drug Report 2008, available at http:// www.unodc.org/documents/wdr/WDR_2008/WDR_2008_eng_web.pdf, accessed January 2010.

Samuel Adu-Gyamfi \& Brenya, Edward. 17

Ibid

Ibid

6 Ghana education service," A teacher's guide on the prevention of drug abuse in schools," Overview of the Drug Situation in Ghana", (Paris, Versailles publication April 1995)20.

7 A Borrofica, "Mental illness and Indian hemp in Lagos, Nigeria", East African Medical Journal, vol.43. (3) (1996):8084.

8 United Nations "United Nations Office on Drugs and Crime (UNODC). 2008 World Drug Report 2008, available at http:// www.unodc.org/documents/wdr/WDR_2008/WDR_2008_eng_web.pdf, accessed January 2010.

$9 \quad$ Ibid

10 Adeyemi, Adebayo, «Ntampi smoking - Ghana is Third!” Ghana web, July 9, 2007. Accessed March 2, 2015, http://www. ghanaweb.com/GhanaHomePage/NewsArchive/artikel.php?ID=126884.

11 Ibid

12 E. C, Dogbe "Drug Abuse among Students of Second Cycle Institutions: A case study of The Tema Secondary School" (Masters thesis, university of Ghana, Dept. of Sociology UG, 2003)

13 Houghton Mifflin Company, The American Heritage, 'Definition of marijuana', Dictionary of the English Language, 4th edition, updated in 2009, (published by Houghton Mifflin Company) www.thefreedictionary.com/reforms.

14 Samuel Adu-Gyamfi \& Brenya, Edward. "Re-hushing commentaries on the effect and potential benefit of cannabis: lessons Ghana can learn from USA and Canada," Global Journal of Interdisciplinary Social Science, Vol.3 (3), (2014): 10-20. Accessed October 9, 2014. Url: file http://www.gifre.org/admin/papers/gjiss/10-20-RE-HUSHING \%20-vol-3-3-gjiss.pdf

15 Samuel Adu-Gyamfi \& Edward Brenya, 10.

16 National Survey Results on Drug Use from The Monitoring The Future Study, 1975-1997

17 A. S. Hornby, Oxford Advanced Learner's Dictionary, 6th Edition, ed. Sally Wehmeier, Phonetics Editor, Michael Ashby (Oxford University Press), 9.

18 Webster's 1913 dictionary, 'Definition of marijuana," www.hyperdictionary.com/dictionary/policy, November 4, 2014. Accessed from www.knust.edu.gh.oer/pages/index.

19 United Nation office on Drugs and Crime, 2008. Accessed November 18, 2014. Available http://www.undcp.org/ report_1999-06-01_1.htm.

20 Odejide Adebayo Olabisi "Psycho-Social Features of In-Patients in Long Stay Psychiatric Hospitals: A Cross Cultural Study" (M.D. Thesis, University of Ibadan, 1985), 52.

21 Helena Selby, "Marijuana (Ntampi) usage in Ghana", The Chronicle, May 4,2011, accessed February 5, 2015 http://thechronicle.com.gh/marijuana-ntampi-usage-in-ghana.

22 ibid

23 ibid

24 Samuel Adu-Gyamfi \& Edward Brenya, 13.

25 Adebayo Olabisi Odejide, "Mental illness and Indian hemp in Lagos, Nigeria", East African Medical Journal 43, no.8 (1966), 377-84.

26 Emmanuel Akyeampong: Addiction to Alcohol and Drugs in Urban Environments February 10, 2010. Accessed October 15, 2014. Available from http://www.ifra-nigeria.org/IMG/pdf/Akyeampong_2010.pdf

27 Emmanuel Akyeampong, “'What is in a drink?: Class struggle, popular culture and the politics of akpeteshie (local gin) in Ghana, 1930-1967," Journal of African History 37, no.2 (1996):215-36.

28 T. A. Lambo, "Medical and Social Problems of Drug Addiction in West Africa," The West African Medical Journal 11, no. 3(1965), 236-54

29 Salifu Abdul-Rahaman, “Akpeteshie laced with wee, police swoop on producer,” Daily Graphic, November 20, 2001. 
$30 \quad$ Samuel Adu-Gyamfi \& Edward Brenya, 14

31 Freeman koryekpor Awulesu, "5000 people abuse drug in Ghana resulting in 70 mad cases," June 19, 2014, accessed November 18, 2014. http://www.todaygh.com/2014/11/18/50000-people-abuse-drugs-ghana-resulting-70-mad-cases,

32 Samuel Adu-Gyamfi \& Edward Brenya, "Re-hushing commentaries on the effect and potential benefit of cannabis: lessons Ghana can learn from USA AND CANADA", Vol.3 (3):15, ISSN: 2319-8834, (2014):16.Accessed October 9, 2014. Url: file http://www.gifre.org/admin/papers/gjiss/10-20-RE-HUSHING \%20-vol-3-3-gjiss.pdf.

33 Helena Selby, "Marijuana (ntampi) usage in Ghana," The Chronicle, May 4, 2011, accessed November 18, 2014, http:// thechronicle.com.gh/?p=23371.

34 Samuel Adu-Gyamfi \& Edward Brenya, 17

35 Ibid

36 Ibid

37 Drug Abuse worldwide, 2009 (accessed October 14, 2015) Available from http://www.undcp.org/pdf/report

38 Daniel Ganul, "Religious Factors and the Use of Drugs among seventh day Adventists in Ghana," vol. 3(5):101, ISSN: 2225-093X, (2013):101. Accessed November 21, 2014. URL: www.iiste.org.

39 Adeyemi. Adebayo, «Ntampi smoking - Ghana is Third!" Ghana web, July 9, 2007. Accessed March 2, 2015. http://www. todaygh.com/,50000-people-abuse-drugs-ghana-resulting-70-mad-cases.

40 William Dewey, "Drug abuse and addiction, Research Report Series: Cannabis Abuse", Friends of NIDA, January 3, 2010, http://www.nida.nih.gov/NIDAHome.html

41 Ibid

42 Ibid

43 Samuel Adu-Gyamfi \& Edward Brenya, 10.

44 Ibid

45 Ibid

46 Duncan J. Watt "Premature mortality among males with substance use disorders. Addictive Behavior." American Journal of Sociology 115 (2009): 405-50. Accessed February 28, 2015. Doi: 10.1086/599247.

47 Ibid

48 Ibid

49 Ibid

50 Henry, K. L., Smith, E. A., \& Caldwell, L. L, Deterioration of academic achievement and marijuana use onset among rural adolescents, Health Education Research, (Evanston, IL :Northwestern University,2007), 372-384.

51 Room, R., Fischer, B., Hall, W. Lenton, S. and Reuter, P, Cannabis Policy: Moving Beyond Stalemate, (Oxford, UK: Oxford University Press, 2010), 28

52 Dewey William, "Drug abuse and addiction, Research Report Series: Cannabis Abuse”, Friends of NIDA, January 3, 2010. Accessed October 30, 2014. Available from http://www.nida.nih.gov/NIDAHome.html.

53 "Global facts about substance abuse, "World Health Organization, Last modified November 18, 2014. http://www.who.int/ substance abuse/facts/global burden/en/index.htm.

54 Ibid

55 Fergusson, D. M and Horwood, L. J, "Does cannabis use encourage other forms of illicit drug use? Addiction (Armonk, NY: M.E.Sharpe, 2000) 95.

56 Henry Bernstien, "Ghana's Drug Economy: Some Preliminary Data on drug abuse”, (San Francisco, ROAPE Publications Ltd., 1999)18.

57 Y.H Affinih, "A Preliminary Study of Drug Abuse and its Mental Health and Health Consequences among Addicts in Greater Accra," Journal of Psychoactive Drugs, 31, no. 4 (1999) 395-403.

58 Edward Smith Thomas, "Reviewing Adolescent Marijuana Abuse" Rev. of Cloudsplitter, by Russel Banks. New York Times Book Review 13 October, 2005: pg. 17.

$59 \quad$ Ibid

60 Ibid

${ }^{61}$ S.L. Brown. \& L.N Rineli "Family structure, family processes, and adolescent smoking and drinking", Journal of Research on Adolescent 20, no.3(2010) : 259-273

62 Sanjung Goupta, "Medical Facts of Marijuana: a Weed Documentary," A journal on medical fact on marijuana, 73.no 2. (2008)53-55.

63 Ibid

64 Samuel Adu-Gyamfi \& Edward Brenya, 12.

65 Ibid

66 Ibid

67 Adeyemi, Adebayo, «Ntampi smoking - Ghana is Third!” Ghana web, July 9, 2007. Accessed March 2, 2015, http://www. ghanaweb.com/GhanaHomePage/NewsArchive/artikel.php?ID=126884.

68 ibid

69 Richard Appiah, “End of debate: Let marijuana remain illegal.” Today Ghana, March, 24 2014. Accessed February 6, 2015. http://www.todaygh.com.

${ }^{70}$ "Cannabis search”, Cannabis History, Last modified December 5, 2011. Available from http://www.cannabissearch.com/ history.

71 Ibid

72 Ibid

73 Ibid 
74 “A Brief History of Marijuana Use in Ancient Times,” History of marijuana, Last modified March 11, 2009. Available from http://www.examiner.com/article/a-brief-history-of-marijuana-use-ancient-africa.

75 Ibid

76 Ibid

Ibid

Ibid

K. Zetterstrom, "Bena Riamba, Brothers of the Hemp,” Studia Ethnographica Upsaliensia, 26 (1966): 151-65

Ibid

Lester Grinspoon, "History of Cannabis as a Medicine,” August 16, 2005

Ibid

83 A Signal of Misunderstanding, the Report of the US National Commission on Marihuana and Drug Abuse, 1972. Accessed April 15, 2015. Available from http://www.erowid.com

84 Ibid

85 Ibid

86 A Signal of Misunderstanding, the Report of the US National Commission on Marihuana and Drug Abuse, 1972(accessed April 15, 2015): available from http://www.erowid.com

87 Ibid

88 "A Brief History of Marijuana Use in Ancient Times," History of marijuana, Last modified March 11, 2009, http://www. examiner.com/article/a-brief-history-of-marijuana-use-ancient-africa.

89 Bernard A. Akeia, “The Material Roots of Rastafarian Marijuana Symbolism”, History and Anthropology, (Routledge, Informa Press Ltd, England 2007)89-99.

90 H. von Wissman, My Second Journey through Equatorial Africa (London: Chatto \& Windus publication, 1891$) 312$.

91 Ibid

92 Ibid

3 Ibid

94 Ibid

95 Emmanuel Akyeampong: Addiction to Alcohol and Drugs in Urban Environments February 10, 2010. Accessed October 15, 2014. Available from http://www.ifra-nigeria.org/IMG/pdf/Akyeampong_2010.pdf

$96 \quad$ Ibid

$97 \quad$ Ibid

$98 \quad$ Ibid

99 Stephen Addae, "A Short History of the Ghana Armed Forces" (Accra: Graphic Packaging Limited, 2005), 34.

100 Emmanuel Akyeampong, "Addiction to Alcohol and Drugs in Urban Environments", http://www.ifra-nigeria.org/IMG/ pdf/Akyeampong_2010.pdf.10/02/2010

101 Neil Savishinsky, "Rastafari in the Promised Land: The Spread of a Jamaican Socio-Religious Movement among the Youth of West Africa," African Studies Review, 37: 3 (1994), 19-50

102 Ibid

103 Emmanuel Akyeampong, "Addiction to Alcohol and Drugs in Urban Environments", http://www.ifra-nigeria.org/IMG/ pdf/Akyeampong_2010.pdf.10/02/2010

104 Daily Graphic, April 19, 1994.

105 Ibid

106 Ghanaian Times, January 16, 1999

107 Information from an informant in Baby Brunei, Block J, April 7, 2015

108 Ibid

109 Ibid

$110 \quad$ Ibid

111 Ibid

112 Ibid

113 Information from an informant in the bush where marijuana is smoked in a bush located behind unity hall canteen, April 7, 2015.

114 Information from an informant in Evandi Hostel, Old block April 7, 2015

115 Information from an informant in the bush where marijuana is smoked in a bush located behind unity hall canteen, April 8,2015

116 Ibid

$117 \quad$ Ibid

118 Information from an informant in Georgia hostel, fourth floor April 10, 2015

119 Kwame Nkrumah University of Science and Technology, Students' Guide, Ed. Dean of Students, KNUST, (University Printing Press, KNUST, Revised and Reprinted June 2013), 45.

120 Ibid

121 Ibid

\section{References}

Abdul-Rahaman, S. (2001) Akpeteshie laced with wee, police swoop on producer. Daily Graphic, 20 November 2001. 
A Brief History of Marijuana Use in Ancient Times. History of marijuana, Last modified. March 11, 2009, http://www.examiner.com/article/a-brief-history-of-marijuana-use-ancientafrica

Adebayo, O. O. (1966). Mental illness and Indian hemp in Lagos, Nigeria. East African Medical Journal, 43.

Adelekan, M. L., Ndom, R.J.E. (1997) Trends in prevalence and pattern of substance use among secondary school students in Ilorin, Nigeria. West African Journal of Medicine, 16.

Adu-Gyamfi, S. \& Brenya, E. (2014) Re-hushing commentaries on the effect. Journal of Interdisciplinary Social Science, 3(3).

Akeia, B. The Material Roots of Rastafarian Marijuana Symbolism. History and Anthropology. Routledge, Informa Press Ltd, 2007.

Akyeampong, E. (1996). What is in a drink? : Class struggle, popular culture and the politics of akpeteshie (local gin) in Ghana, 1930-1967. Journal of African History, 37(2).

Appiah, R. (2014). End of debate: Let marijuana remain illegal. Today Ghana, March, 24.

Appiah, R. (2015). End of debate: Let marijuana remain illegal. Today Ghana, http://www.todaygh. com. Accessed February, 6.

A Signal of Misunderstanding, the Report of the US National Commission on Marihuana and Drug Abuse, 1972, available from http://www.erowid.com. Accessed April 15, 2015.

Assabil, J. K. Abuse of psychotropic substances- a survey of some first and second cycle institutions in the Bosomtwi and Atwima-Kwanwoma district in Ashanti Region of Ghana. MSc Dissertation, Kwame Nkrumah University of Science and Technology, 2010.

Awulesu, F. 5000 people abuse drug in Ghana resulting in 70 mad cases. June 19, 2014, accessed November 18, 2014.

Chen, A.J., Emmanuel, S.C., Ho, C.K. (1990). Cigarette smoking among school Children in Singapore. Singapore Med. Journal. PMID: 2392697.

Degenhardt, L. \& Hall, W. Illicit drugs as risk factors: some definitions. Global Burden of Disease Mental Disorders and Illicit Drug Use Expert Group. Illicit drugs discussion paper 8. National Drug and Alcohol Research Centre, Sydney, University of NSW printing press, 2008.

Dogbe, E.C. Drug Abuse among Students of Second Cycle Institutions: A case study of The Tema Secondary School. Masters thesis, university of Ghana, Dept. of Sociology UG, 2003.

Duncan, J. W. (2009). Premature mortality among males with substance use disorders. Addictive Behavior. American Journal of Sociology, 115.

Fergusson, D. M. \& Horwood, L. J. Does cannabis use encourage other forms of illicit drug use? Addiction. New Jersey, Princeton University Press, 2000.

Ganu, D. (2013). Religious Factors and the Use of Drugs among Seventh day. Adventists in Ghana, 3(5), 101.

Ghana News Agency. Drug Abuse among Students of Second Cycle Institutions. The Pioneer, October 3, 2006.

Hornby, A. S. Oxford Advanced Learner's Dictionary. 6th Edition, ed. Sally Wehmeier and Phonetics Editor, Michael Ashby, Oxford University Press, 2000.

Lambo, T. A. (1965). Medical and Social Problems of Drug Addiction in West Africa. The West African Medical Journal, December. 
Ntowbea, C. Prevalence of substance use among Junior high school pupils in Dangme West District. BA. Dissertation, University Of Ghana, 2010.

Selby, H. (2011). Marijuana (ntampi) usage in Ghana. The Chronicle, May, 4.

United Nations Office on Drugs and Crime (UNODC). World Drug Report 2008. http://www. unodc.org/documents/wdr/WDR_2008/WDR_2008_eng_web.pdf. Accessed January 14, 2015.

Weinberg, N. Z. Risk Factors for Adolescent Substance Abuse. Journal of Learning disabilities. http://www.highbeam.com/doc/1G1-76751504. Accessed March 8, 2010.

William, D. Drug abuse and addiction, Research Report Series: Cannabis Abuse. Friends of NIDA, January 3, 2010, http://www.nida.nih.gov/NIDAHome.html. Accessed January 14, 2015

Wissman, H. von. My Second Journey through Equatorial Africa. London, Chatto \& Windus publication, 1891.

World Health Organization, "Alcohol and Young People", Last modified November 18, 2014. http://www.who.int/substance_abuse/facts/global_burden/en/index.htm. Accessed March 22, 2015.

\title{
Употребление марихуаны в Университете Ганы: исследование
}

\author{
Самуэль Аду-Гуамфи, Эдвард Бренья \\ Университет науки и технологии \\ им. Кваме Нкрума (KNUST) \\ Гана
}

В настоящей статье исследуется вопрос употребления марихуаны студентами Университетов Ганы. Для сбора информацчи среди употребляюших наркотик студентов были разработаны специиальные вопросы для интервью. Особое внимание уделялось тематическим областям, которыми изобилует существующая литература, касающаяся употребления марихуаны и последствий ее применения для студентов. Рассматриваются факторы, которые приводят к использованию наркотика студентами, и то, как употребление марихуаны влияет на их студенческую деятельность. Выводы, проистекающие из данного исследования, а также данные исследования должны послужить базой для администрации университетов и преподавателей, чтобы объединить усилия в области организаџии тренингов для коллег и консультационных подразделений в университетах Африки и Ганы в частности.

Ключевые слова: марихуана, употребление наркотиков, студенты, Университет Ганыл.

Научная специиальность: 23.00.00 - политология, 07.00.00-исторические науки. 